\title{
Value Orientation as a Moderator on Self-stigma in People with Mental Illness
}

\author{
Sofia Hsiou-Huei Lai \\ Graduate Institute of Counseling Psychology \& Rehabilitation Counseling, National Kaohsiung Normal University, Taiwan
}

Copyright $(2016$ by authors, all rights reserved. Authors agree that this article remains permanently open access under the terms of the Creative Commons Attribution License 4.0 International License

\begin{abstract}
This study explores whether the self-stigma in people with mental illness is moderated by value orientation -- collectivism and individualism. A model of value orientation and self-stigmatization was depicted and tested with data collected in Taiwan, where 182 subjects voluntarily participated in the survey. The model demonstrated the ideas that collectivism thoughts alleviate self-stigma, while individualism beliefs strengthen the stigmatization process. All the hypotheses, including a measurement structure, a causal path with covariate variable and two separate moderator effects, were significantly supported. Implications of the findings for academicians and practitioners in psychiatric rehabilitation were discussed.
\end{abstract}

Keywords Value Orientation, Collectivism, Self-stigma, Self-efficacy, Psychiatric Rehabilitation Counseling

\section{Introduction}

Self-stigma in people with mental illness refers to signs or experiences of disgrace through which the victims internalize and self-inflict the social stigma against themselves [1]. Unwillingness to seek mental health services, failure to adhere to treatment regimens [2], reluctance to pursue employment and independent living opportunities [3], impaired self-efficacy, and diminished self-esteem[4] are among the detrimental consequences of the self-stigmatization.

In American and the Pan-Pacific Region, most of the helping professionals are trained from the predominantly Occidental perspectives [5]. Many assumptions in various approaches of psychological counseling have developed from the Western culture and the medical technologies. Among the particular value orientation, for example, individualism and personal independence are two essential pillars of the Western culture. Consequently, many counseling theories, goals, strategies and processes are based on the individualistic assumptions [6]. However, the individualistic assumptions usually leads to inadequate services for clients who have a collectivistic cultural background, in particular for clients who have Confucian or Chinese heritages [7]. Moreover, many counseling practices and interventions derived from the individualistic assumptions may be inappropriate (or even worse, antagonistic) to the lifestyles and cultural values of the Oriental society [8]. In a collectivist society, the collective welfare and societal harmony are emphasized more than self-fulfillment and individual achievement; forbearance and compliance are valued higher than individual assertiveness and independence [9]. For instance, a collectivism-oriented client who restraint himself of strong feelings may be viewed by an individualism-oriented counselor as repressed, inhibited, or unassertive. Even worst, counseling strategies and interventions may lead the clients to violate their important values and may dictate in their lifestyle and cultural background.

Regarding rehabilitation for people with mental illness, especially the problem of self-stigma, the difficulties derived from different value orientations have existed and hindered the progress of recovery [10]. This paper explores whether self-stigma in people with mental illness is moderated by value orientation. Meanwhile, the author critically reviewed the literature regarding self-stigma and value orientations, then depicted a model of value orientation and self-stigmatization. The model, while includes two "psychological-proximal variables" of cultural phenomenon research--collectivism and individualism [11], will be tested through a "correlational research design" [12] and hierarchical regression analyses with survey data collected in Taiwan. Implications of the findings for academicians and practitioners in psychiatric rehabilitation counseling were discussed.

\section{Self-Stigma and Value Orientation}

\subsection{Self-stigmatization}

Social psychologists have described self-stigmatization in 
terms of cognitive structures: stereotype awareness, stereotype agreement, and self-concurrence [1]. Awareness of stereotypes is merely a necessary condition, that it will not necessarily lead to agreement with them. However, as Link and his associates [4] point out, once having agreed with the stereotype, the victims may start to think of themselves as having the negative attributes. Following the secondary deviance theory [13] and the principle of self-fulfilling prophecies [14], it is theorized that a person who agrees with the social labeling has little choice but to conform to the conviction of that stigma. Self-concurrence refers to the extent by which persons with mental illness "internalize" the social stigma, and accordingly devaluate and discriminate against themselves [15]. In summary, the predictive power of stereotype agreement on self-concurrence (i.e., self-stigma) is substantial and critical.

Self-efficacy refers to the extent which a person with mental illness believes in his or her ability to implement living or work-related tasks [16]. Self-efficacy involves self-awareness in which people are aware of their traits, identity and abilities [17]. Many researchers consider self-efficacy as one of the major goals of psychiatric rehabilitation and deem it as an indicator for self-stigma $[10,18,19]$. Meanwhile, depression is usually a concomitant symptom which occurs with mental disorders [20,21]. Many researchers claim that depression per se may largely account for low self-efficacy [1,22,23]. For example, persons with schizophrenia often experience morbid depression that can manifest itself as low self-efficacy. In these instances, it is not clear whether the diminished self-efficacy is due solely to depression or also to the effect of self-stigma. Therefore, to strictly test the effect of stereotype agreement on self-efficacy, it is desirable to firstly partial out the covariate of depression. In sum, the author predicts that Stereotype Agreement has a negative effect on Self-Efficacy, with Depression being firstly dealt with as a control variable $\left(\mathrm{H}_{1}\right)$.

\subsection{Value Orientation}

Triandis[24] maintains that "perhaps the most important dimension of cultural difference in social behavior, across the diverse cultures of the world, is the relative emphasis on individualism versus collectivism"(p.42). According to Triandis's definitions, individualism and collectivism are two separately dimensions, rather than of opposite direction in one dimension [25]. Although these two are differentiated in the degree of separateness and connectedness between individuals and their groups, individualism and collectivism are in nature two psychological attributes (or called "proximal variables" in cross-cultural research) which may associate with personality traits and can be coexisting and ambivalent $[11,17,25]$. Individualism, on one hand, stresses that self-worth is measured by personal achievement and that the individual is believed to be in control of his or her own destiny. Actions are motivated through one's own thoughts, feelings and determination. Individualism evokes a strong aspiration for individuals to be autonomous, self-directing, and assertive, leading to expressing their own capability. Collectivism, on the other hand, emphasizes that people living in a society are linked in webs of interrelation and are situated in different roles and statuses. Following the collectivist thoughts, people are encouraged to put the group's interests before their own and to earnestly fulfill prescribed duties and obligations in the groups. In a collectivist society, the collective welfare and societal harmony are emphasized more than self-fulfillment and individual achievement; forbearance and compliance are valued higher than individual assertiveness and independence.

It is believed that Occidental cultures (e.g., American) tend to embrace individualism, while most of Oriental cultures (Taiwanese, in particular) incline to uphold collectivism [26]. It is worth noting, however, that as acculturation may ensue in a cross-cultural globalization setting nowadays, individuals who originally belong to a collectivist society may adopt to some extents the attitudes, values and behaviors of individualistic culture [27]. Consequently, a positive correlation between individualism and collectivism variables may be presenting in a quantitative analysis of cross-cultural research [28].

Let us address the variable of Collectivism first. For people with mental illness who highly uphold collectivism (group of high Collectivism), they would think that they are linked in webs of social groups and are situated in different roles and statuses in the society. Therefore, their self-concurrence of the social stigma would be alleviated. But, for the group of low Collectivism, no such alleviative effect of internalized stigma would occur. In other words, the author anticipate that for the group of high Collectivism Stereotype Agreement has no significant effect on Self-Efficacy, while for the group of low Collectivism, there is a significant and negative effect between these two variables $\left(\mathrm{H}_{2}\right)$. In sum, the model predicts a moderator effect of Collectivism on the causal linkage from Stereotype Agreement to Self-Efficacy.

For psychiatric patients who highly embrace individualism (group of high Individualism), they would incline to evaluate their self-efficacy in terms of own ability alone. Consequently, their self-concurrence of the social stigma would be strengthened. But, for the group of low Individualism, no such strengthening effect would happen. Thus, for high individualism group, Stereotype Agreement will significantly and negatively impact Self-Efficacy, while for the group of low individualism no significant effect can be found $\left(\mathrm{H}_{3}\right)$. In other words, the author anticipates a moderator effect of Individualism on the causal path from Stereotype Agreement to Self-Efficacy.

In summary, this article depicted a model of value orientation and self-stigmatization, where collectivism and individualism were two moderator variables separately moderating the effect of Stereotype Agreement on Self-Efficacy, with Depression acting as a control variable 
(See Figure 1). For short, the model demonstrated the ideas that collectivism thoughts alleviate self-stigma, while individualism beliefs strengthen the self-stigmatization process.

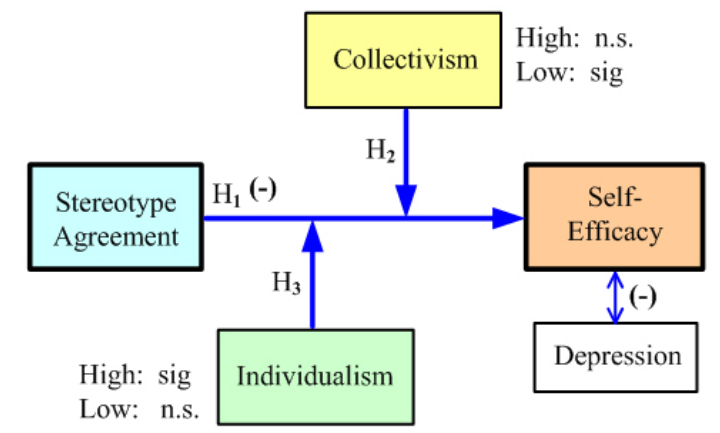

Figure 1. Value Orientation and Self-Stigmatization

\section{Methods}

\subsection{Participants}

One hundred ninety one persons with serious mental illness were recruited in Taiwan and voluntarily participated in the survey. Criteria for recruiting participants for the study included: (1) diagnosis of chronic psychiatric disability from psychiatrist; (2) having previously received or currently receiving psychiatric treatment; and (3) ability to complete a 25-minute paper-and-pencil survey. A total of 182 valid samples were obtained (the valid sample rate equaled 95.3\%); 94 (51.6\%) men and 88 (48.4\%) women. Their ages ranged from 18 to $59(M=37.04 ; S D=9.07)$. Regarding marital status, 141 were singles $(77.5 \%), 18$ married (9.9\%), 21 divorced (11.5\%), and one widowed. For education level, 46 (25.3\%) completed middle school, 105 (57.7\%) high school, and 29 (15.9\%) college degrees, and one with graduate level. With regard to the disorder diagnosed (a multiple responses question), 76.4\% $(n=139)$ had schizophrenia. Only $11.5 \%(n=21)$ and $11.1 \%(n=20)$ had bipolar and schizoaffective, respectively. In terms of history of mental illness, average duration was 10.8 years $(S D=6.6)$.

\subsection{Procedure}

During questionnaire development, to ensure the questions were understandable and suitable for the participants, focus-group interviews and then a pretest survey were held in a municipal psychiatry hospital in Kaohsiung, Taiwan. For the large-scale survey, participants were recruited through nine member associations of the Alliance for the Mentally Ill in Taiwan (TAMI), located in the Northern, Central, and Southern areas of the country. The AMIs (Associations of the Mentally Ill) are grassroots and self-help organizations of people with mental illnesses and their families and friends. It took about 25 minutes to complete the survey. A gift certificate to a convenient store (NT\$ 100, about US\$ 3.00) was offered as a token of appreciation to each participant for completing the questionnaire.

\subsection{Measures}

The measures for Stereotype Agreement were adopted from the Self-Stigma of Mental Illness Scales (SSMIS[1]). Although the original nine items of the SSMIS were used to collect data, the present study selected only 7 items of them for further analysis (see Appendix for the measure items selected). The item selection was based on: (a) results of reliability analyses and construct validity assessment, and (b) balance in number of question with other constructs in the model. To measure Self-Efficacy, the author adopted items from Sherer's General Self-Efficacy Scale (GSES[16]). The original number of items of GSES is 17. Likewise, using the same method above, the author selected only 7 items of them for further analysis. For measure regarding Depression, items were adopted from a Taiwanese Depression Scale (TDS[23]), whose original number of items were 18. Similarly, using the same method above, 7 items of them were selected. To measure Collectivism and Individualism, the author adopted 6 and 4 question items, respectively, from Triandis and Gelfand's[29] measure inventory for value orientation.

The question sets selected and used to measure the study constructs obtained fair to excellent index for their individual reliabilities. The Cronbach's alphas from reliability tests for Stereotype Agreement, Self-Efficacy, Depression, Collectivism, and Individualism were .863 ( 7 items), .830 ( 7 items), .906 (7 items), .784 (6 items) and .727 (4 items), respectively (see Appendix for details of the reliability validation). Moreover, to verify the measures' discriminant validity and construct validity, the author conducted both exploratory and confirmatory factor analyses (EFA and CFA), on the whole 31-question set of the 5 variables. From both of the particular factor analyses, the result presented a clear factor loading pattern, exactly the same as what the author posited them to measure (details of the result are available on request).

\section{Results}

Means, standard deviations, and correlations of the study variables are presented in Table 1. In terms of the scale means, the score of Stereotypes Agreement is considerably low (3.97 or $44.1 \%$ of the range) and the score of Self-Efficacy is slightly high (3.24 or $64.8 \%$ of the range). Between Stereotype Agreement and Self-Efficacy, the coefficients of correlation were -.373 with high significance $(\mathrm{p}=.000)$. Between Depression and Self-Efficacy, the coefficients was substantial $(\mathrm{R}=-.496)$ and highly significant $(\mathrm{p}=.000)$, that supports the idea that Depression needs to be dealt with as a control variable. Moreover, the positive correlation between Collectivism and Individualism 
is consistent with the conceptualization of cultural-syndrome dimensions aforementioned [28,29].

It is anticipated that Stereotype Agreement has a negative effect on Self-Efficacy with Depression as a covariate $\left(\mathrm{H}_{1}\right)$. To test this hypothesis, hierarchical regression analysis was applied. As shown in Table 2, on the first model where Depression acted as a single independent variable, it was significant and well accounted for $\left(F=50.990, \mathrm{R}^{2}=.232, \mathrm{p}\right.$ $=.000)$. This result confirmed that Depression can be a covariate variable for a further advanced model.

For the full model, at the first step Depression as a covariate variable was significant $\left(\beta_{1}=-.402, \mathrm{t}=-5.772\right.$, $\mathrm{p}=.000)$. Then, the regression coefficient of Stereotype Agreement $\left(\beta_{2}\right.$, the major predictive variable) was -.232 with high significance $(t=-3.326, p=.001)$. Meanwhile, for the full model, excellent indexes of goodness-of-fit and the model effectiveness $\left(\mathrm{F}=32.544 ; \mathrm{R}^{2}=.279, \mathrm{p}=.000\right)$ were obtained. Thus, $\mathrm{H}_{1}$ was supported.

Table 1. Means, Standard Deviations and Correlations

\begin{tabular}{|c|c|c|c|c|c|}
\hline Constructs & $\operatorname{Mean}^{\mathrm{a}}(\mathrm{SD})$ & $\begin{array}{l}\text { Stereotype } \\
\text { Agreement }\end{array}$ & Self-efficacy & $\begin{array}{c}\text { Collecti- } \\
\text { vism }\end{array}$ & $\begin{array}{l}\text { Individual- } \\
\text { ism }\end{array}$ \\
\hline Stereotype Agreement & $3.97(1.81)$ & 1 & & & \\
\hline Self-Efficacy & $3.24(.72)$ & $-.373 * * *$ & 1 & & \\
\hline Collectivism & $5.47(.87)$ & $-.249 * *$ & .121 & 1 & \\
\hline Individualism & $4.60(1.20)$ & -.038 & -.069 & $.366 * * *$ & 1 \\
\hline Depression & $1.90(.73)$ & $.332 * * *$ & $-.496 * * *$ & $-.161 *$ & .108 \\
\hline
\end{tabular}

Table 2. Hierarchical Regression Analyses of Self-Efficacy on Stereotype Agreement

\begin{tabular}{|c|c|c|c|c|}
\hline \multicolumn{5}{|c|}{ Dependent Variable: Self-Efficacy } \\
\hline \multirow[b]{2}{*}{ Model } & \multicolumn{2}{|c|}{ Independent Variable } & \multirow{2}{*}{$\begin{array}{c}\text { Incremental } \\
\mathrm{R}^{2}\end{array}$} & \multirow{2}{*}{$\begin{array}{c}\text { Total } \\
\mathrm{R}^{2}\end{array}$} \\
\hline & Depression & $\begin{array}{c}\text { Stereotype } \\
\text { Agreement }\end{array}$ & & \\
\hline Control Var. & $\begin{array}{c}\beta=-.481 * * * \\
(\mathrm{t}=-7.141 \\
\mathrm{p}=.000)\end{array}$ & -- & $\begin{array}{c}.232 * * * \\
(\mathrm{~F}=50.990 \\
\mathrm{p}=.000)\end{array}$ & $\begin{array}{c}.232 * * * \\
(\mathrm{~F}=50.990 \\
\mathrm{p}=.000)\end{array}$ \\
\hline Full Model. & $\begin{array}{c}\beta_{1}=-.402 * * * \\
(\mathrm{t}=-5.772 \\
\mathrm{p}=.000)\end{array}$ & $\begin{array}{c}\beta_{2}=-.232 * * \\
(\mathrm{t}=-3.326 \\
\mathrm{p}=.001)\end{array}$ & $\begin{array}{c}.047 * * \\
(\mathrm{~F}=11.061 \\
\mathrm{p}=.001)\end{array}$ & $\begin{array}{c}.279 * * * \\
(\mathrm{~F}=32.544 \\
\mathrm{p}=.000)\end{array}$ \\
\hline
\end{tabular}
$\mathrm{n}=171 ; * * * \mathrm{p}<.001 ; * *: \mathrm{p}<.01$

Table 3. Regression Analyses of Self-Efficacy on Stereotype Agreement: High vs. Low Collectivism

\begin{tabular}{|c|c|c|c|c|c|}
\hline \multicolumn{6}{|c|}{ Dependent Variable: Self-Efficacy } \\
\hline \multirow[b]{2}{*}{ Collectivism } & \multicolumn{2}{|c|}{ Independent Variable } & \multirow{2}{*}{$\begin{array}{c}\text { Incremental } \\
\mathrm{R}^{2}\end{array}$} & \multirow{2}{*}{$\begin{array}{c}\text { Total } \\
\mathrm{R}^{2}\end{array}$} & \multirow[b]{2}{*}{ VIF } \\
\hline & $\begin{array}{l}\text { Depression } \\
\text { (control var.) }\end{array}$ & $\begin{array}{c}\text { Stereotype } \\
\text { Agreement }\end{array}$ & & & \\
\hline $\begin{array}{l}\text { High } \\
(\mathrm{n}=83)\end{array}$ & $\begin{array}{c}\beta_{1}=-.436^{* * *} \\
(\mathrm{t}=-4.382 \\
\mathrm{p}=.000)\end{array}$ & $\begin{array}{c}\beta_{2}=-.189 \\
(\mathrm{t}=-1.905 \\
\mathrm{p}=.060)\end{array}$ & $\begin{array}{c}.033 \\
(\mathrm{~F}=3.629 \\
\mathrm{p}=.060)\end{array}$ & $\begin{array}{c}.273^{* * *} \\
(\mathrm{~F}=15.011 \\
\mathrm{p}=.000)\end{array}$ & 1.08 \\
\hline $\begin{array}{l}\text { Low } \\
(\mathrm{n}=79)\end{array}$ & $\begin{array}{c}\beta_{1}=-.323^{* *} \\
(\mathrm{t}=-3.111 \\
\mathrm{p}=.003)\end{array}$ & $\begin{array}{c}\beta_{2}=-.300^{* *} \\
(\mathrm{t}=-2.892 \\
\mathrm{p}=.005)\end{array}$ & $\begin{array}{c}.083^{* *} \\
(\mathrm{~F}=8.366 \\
\mathrm{p}=.005)\end{array}$ & $\begin{array}{c}.249^{* * *} \\
(\mathrm{~F}=12.581 \\
\mathrm{p}=.000)\end{array}$ & 1.08 \\
\hline
\end{tabular}
$* * *: \mathrm{p}<.001 ; * *: \mathrm{p}<.01$

Table 4. Regression Analyses of Self-Efficacy on Stereotype Agreement: High vs. Low Individualism

\begin{tabular}{|c|c|c|c|c|c|}
\hline \multicolumn{6}{|c|}{ Dependent Variable: Self-Efficacy } \\
\hline \multirow[b]{2}{*}{ Individualism } & \multicolumn{2}{|c|}{ Independent Variable } & \multirow{2}{*}{$\begin{array}{c}\text { Incremental } \\
\mathrm{R}^{2}\end{array}$} & \multirow{2}{*}{$\begin{array}{c}\text { Total } \\
\mathrm{R}^{2}\end{array}$} & \multirow[b]{2}{*}{ VIF } \\
\hline & $\begin{array}{c}\text { Depression } \\
\text { (Control var.) }\end{array}$ & $\begin{array}{l}\text { Stereotype } \\
\text { Agreement }\end{array}$ & & & \\
\hline $\begin{array}{l}\text { High } \\
(\mathrm{n}=82)\end{array}$ & $\begin{array}{c}\beta_{1}=-.405^{* * *} \\
(\mathrm{t}=-4.273 \\
\mathrm{p}=.000)\end{array}$ & $\begin{array}{c}\beta_{2}=-.335^{* *} \\
(\mathrm{t}=-3.536 \\
\mathrm{p}=.001)\end{array}$ & $\begin{array}{c}.101 * * \\
(\mathrm{~F}=12.501 \\
\mathrm{p}=.001)\end{array}$ & $\begin{array}{c}.361 * * * \\
(\mathrm{~F}=22.281 \\
\mathrm{p}=.000)\end{array}$ & 1.10 \\
\hline $\begin{array}{l}\text { Low } \\
(\mathrm{n}=80)\end{array}$ & $\begin{array}{c}\beta_{1}=-.343^{* *} \\
(\mathrm{t}=-3.117 \\
\mathrm{p}=.003)\end{array}$ & $\begin{array}{c}\beta_{2}=-.124 \\
(\mathrm{t}=-1.128 \\
\mathrm{p}=.263)\end{array}$ & $\begin{array}{c}.014 \\
(\mathrm{~F}=1.721 \\
\mathrm{p}=.263)\end{array}$ & $\begin{array}{c}.160 * * \\
(\mathrm{~F}=7.317 \\
\mathrm{p}=.001)\end{array}$ & 1.11 \\
\hline
\end{tabular}


To test the hypothesis regarding Collectivism as a moderator, we first split the sample into two groups by the mean of Collectivism, which was 5.47 (see Table 1). Then, hierarchical regressions of Self-Efficacy on Stereotype Agreement with Depression as a covariate were conducted, separately for each group. As shown in Table 3, no significant causal relationship from Stereotype Agreement to Self-Efficacy can be found for the high Collectivism group. However, for the low Collectivism group on the other hand, highly significant statistics were obtained; the regression coefficient of Stereotype Agreement was $-.300(\mathrm{t}=-2.892$, $\mathrm{p}=.005)$, with incremental $\mathrm{R}^{2}$ equaled $.083(\mathrm{~F}=8.366, \mathrm{p}=$ 005). Thus, $\mathrm{H}_{2}$ of Collectivism as a moderator variable was supported.

Hypothesis 3 predicted a moderator effect of Individualism on the causal relationship from Stereotype Agreement to Self-Efficacy. To test $\mathrm{H}_{3}$, similarly as $\mathrm{H}_{2}$, we split the sample into two divisions by the mean of Individualism, which equaled 4.60 (see Table 1). Then, hierarchical regressions of Self-Efficacy on Stereotype Agreement with Depression as a covariate were conducted, separately for each group. As shown in Table 4, for the high Individualism group, the regression coefficient of Stereotype Agreement $\left(\beta_{2}\right)$ was significantly $-.335(\mathrm{t}=$ -3.536, $\mathrm{p}=.001)$, with incremental $\mathrm{R}^{2}$ equaled $.101(\mathrm{~F}=$ $12.501, \mathrm{p}=.001)$. All of the statistics were highly significant. However, for the low Individualism group on the other hand, the regression coefficient of Stereotype Agreement was not significant $(\mathrm{t}=-1.128, \mathrm{p}=.263$; incremental $\mathrm{R}^{2}=.014$ ). Note that the difference between the two total $\mathrm{R}^{2} \mathrm{~s}$ is high as .201. Thus, $\mathrm{H}_{3}$ of Individualism as a moderator variable was supported.

\section{Conclusions}

A model of value orientation and self-stigma in people with mental illness was depicted and tested with high statistical significance in this article. In the model, collectivism and individualism are two moderators separately affecting the effect of stereotype agreement on self-efficacy, while depression acts as a control variable (see Figure 1). In other words, the model proposed that collectivism thoughts alleviates the self-stigma, while individualism beliefs strengthens the self-stigmatization process. These two value orientations interact with both psychosocial and psychopathologic variables, and modulate the self-stigma experience. For instance, regarding the social stigma against mental illness and the internalized stigma, the high-collectivism patients' perception differed significantly from that of the low-collectivism counterparts, that reflected the different worldviews between Occidental and Oriental cultures. As the self-awareness would be modulated differently between the two groups, the perceived self-efficacy of high-collectivists may be linked to their roles and statuses in own social settings, while that of high-individualists may be linked to individual autonomy and competitiveness.

As advocates of multicultural counseling assert, cultural background and ethical value of the clients are critical points for counselors to consider in figuring out better approach and interventions to conduct a psychological counseling. In this vein, moreover, individual differences may need to be paid extended concern, since differences in personality traits exist among members of particular cultural background. Clinicians and counselors need to acquire more understanding of clients as a unique individual, to begin with counseling and process of interventions. The implication of the present research findings would suggest that some tests on psychological "proximal" variables (e.g., individualism and collectivism) be applied in the stage of assessment and diagnosis. When serving clients with high-collectivism thoughts in particular, the counselors may incorporate collectivism, familial bonds and obligations, and well-defined hierarchical social structure into their strategies for a successful psychiatric rehabilitation.

Some limitations of the current study need to be mentioned. Our sample was recruited through nine member associations of the Alliance for the Mentally Ill in Taiwan (TAMI). Although the participants distributed in Northern, Central, and Southern areas of the country, the exact participating sites were chosen by volunteering and willingness to cooperation, not by a random process. Moreover, the self-help TAMIs are operated in a similar style as the clubhouse model of psychiatric rehabilitation, and almost always involve small production activities, such as crafting, small product assembling, and farming. Participants from these institutes may have a better mentality of self-efficacy different from those at large. Finally, regarding directions of future research for rehabilitation of people with mental illness, social structural issues and individuals' capabilities seem to be two promising directions. 


\section{Appendix: Measure Items and Validation}

\begin{tabular}{|c|c|c|}
\hline $\begin{array}{l}\text { Serotype Agreement, adopted from SSMIS }[1] \\
\text { Alpha }=.863, \mathrm{CR}=.816 ; 7 \text { items, } 9 \text {-point Likert scale }\end{array}$ & $\begin{array}{l}\text { Factor } \\
\text { Loading } \\
\text { (EFA) }\end{array}$ & $\begin{array}{l}\text { Std } \underset{\lambda}{ } \\
(\mathrm{CFA})\end{array}$ \\
\hline 1-1. I think people with mental illness are unpredictable. & .794 & .733 \\
\hline 1-2. People with mental illness are dirty and unkempt. & .780 & .747 \\
\hline 1-3. People with mental illness are below average in intelligence. & .765 & .657 \\
\hline 1-4. People with mental illness are dangerous. & .724 & .666 \\
\hline 1-5. People with mental illness cannot be trusted. & .724 & .614 \\
\hline 1-6. People with mental illness are unable to get a regular job. & 697 & 677 \\
\hline 1-7. People with mental illness are unable to take care of themselves. & .696 & .664 \\
\hline \multicolumn{3}{|l|}{$\begin{array}{c}\text { Self-Efficacy, adopted from GSES }[16] \\
\text { Alpha }=.830, \mathrm{CR}=.790 ; 7 \text { items, 5-point Likert scale }\end{array}$} \\
\hline 2-1. I avoid facing difficulties. & .752 & .711 \\
\hline 2-2. I give up on things before completing them. & .748 & .703 \\
\hline 2-3. If something looks complicated, I will not bother to try it. & .711 & .649 \\
\hline 2-4. One of my problems is that I cannot get down to work. & .692 & .621 \\
\hline 2-5. When I set important goals for myself, I rarely achieve them. & .684 & .615 \\
\hline 2-6. When unexpected problems occur, I don't handle them all. & .668 & .591 \\
\hline 2-7. When learning something, I give up if not initially successful. & .667 & .595 \\
\hline \multicolumn{3}{|l|}{$\begin{array}{c}\text { Depression, adopted from TDS }[23] \\
\text { Alpha }=.906, \mathrm{CR}=.853 ; 7 \text { items, 4-point frequency scale }\end{array}$} \\
\hline 3-1. I feel uncomfortable and uneasy. & .840 & .796 \\
\hline 3-2. I feel that I am useless. & .835 & .820 \\
\hline 3-3. I feel tired and weak. & .813 & .691 \\
\hline 3-4. I feel very annoyed. & .809 & .793 \\
\hline 3-5. I feel less confident than before. & .798 & .753 \\
\hline 3-6. I feel physically uneasy. & .760 & .642 \\
\hline 3-7. I have more negative thoughts than before. & .739 & .702 \\
\hline \multicolumn{3}{|l|}{$\begin{array}{l}\text { Collectivism, adopted from Triandis \& Gelfand[29] } \\
\text { Alpha }=.784, \mathrm{CR}=.737 ; 6 \text { items, 7-point Likert scale }\end{array}$} \\
\hline 4-1. I respect the decision what my group made. & .761 & .703 \\
\hline 4-2. I feel good when I cooperate with others. & .740 & .642 \\
\hline 4-3. To me, pleasure is spending time with others. & .711 & .669 \\
\hline 4-4. It is my responsibility to take care of family even if I have to sacrifice self-interest. & .660 & .631 \\
\hline 4-5. Family members have to stay together, no matter what happens. & .649 & .510 \\
\hline 4-6. Parents and children always have to stay together. & .634 & .489 \\
\hline \multicolumn{3}{|l|}{$\begin{array}{l}\text { Individualism, adopted from Triandis \& Gelfand[29] } \\
\text { Alpha }=.727, \mathrm{CR}=.691 ; 4 \text { items, 7-point Likert scale }\end{array}$} \\
\hline 5-1. Winning is everything. & .864 & .905 \\
\hline 5-2. Competition is the law of nature. & .778 & .631 \\
\hline 5-3. It is important that I do my job better than others.. & .733 & .621 \\
\hline 5-4. When another person does better, I get tense and aroused. & .583 & .392 \\
\hline
\end{tabular}

\section{REFERENCES}

[1] P. W. Corrigan, A. C. Watson. L. Barr. The self-stigma of mental illness: Implications for self-esteem and self-efficacy. Journal of Social and Clinical Psychology, Vol.25, No.8, 875-884, 2006.

[2] P. W. Corrigan. How stigma interferes with mental health care. American Psychologist, Vol.59, No.7, 614-625, 2004.

[3] B. G. Link. Understanding labeling effects in the area of mental disorders: An assessment of the effects of expectation of rejection. American Sociological Review, Vol.52, No.1, 96-112, 1987.

[4] B. G. Link, E. L. Struening, S. Neese-Todd, S. M. Asmussen, J. Phelan. Stigma as a barrier to recovery: The consequences of stigma for the self-esteem of people with mental illness. Psychiatric Services, Vol.52, No.12, 1621-1626, 2001.

[5] R. R. Cottone, V. M. Tarvydas. Ethical and Professional Issues in Counseling. Upper Saddle River, NJ: Pearson Education, 2003.

[6] W. H. Cormier, L. S. Cormier. Interviewing strategies for helpers, Pacific Grove, CA: Brooks/Cole, 2011. 
[7] F. Chan, C. S. Lam, P. Leung, X. Fang. Counseling Chinese Americans with disabilities. Journal of Applied Rehabilitation Counseling, Vol.19, No.4, 21-25, 1988.

[8] J. C. Lin. How long do Chinese Americans stay in psychotherapy? Journal of Counseling Psychology, Vol.41, No.3, 288-291, 1994.

[9] D. W. Sue. Asian-American mental health and help-seeking behavior. Journal of Counseling Psychology, Vol.41, No.3, 292-295, 1994.

[10] B. A. Margetić, M. Jakovljević. Socio-cognitive-behavioral structural equation model of internalized stigma in people with severe and persistent mental illness should include personality dimensions. Psychiatry research, Vo.196, No.1, 162-163, 2012.

[11] G. H. Awad, K. O. Cokley. Designing and Interpreting Quantitative Research in Multicultural Counseling. In J. G. Ponterotto, J. M. Casas, L. A. Suzuki, C. M. Alexander, eds. Handbook of Multicultural Counseling, 3rd ed, Thousand Oaks, CA: Sage, 385-396, 2012.

[12] A.E. Kazdin. Research design in clinical psychology, New York: Harper \& Row, 1980.

[13] E. M. Lemert. Social Pathology. New York, NY: McGraw-Hill, 1951.

[14] R. K. Merton. Social Theory and Social Structure. New York, NY: Free Press, 1968.

[15] P. W. Corrigan, A. C. Watson. The paradox of self-stigma and mental illness. Clinical Psychology: Science and Practice, Vol.9, No.1, 35-53, 2002.

[16] M. Sherer, C. H. Adams. Construct validation of the Self-Efficacy Scale. Psychological Reports, Vol.53, 899-902, 1983.

[17] R. J. Crisp, R. N. Turner. Essential social psychology, London: Sage, 2010.

[18] S. Kravetz, M. Faust, M. David. Accepting the mental illness label, perceived control over the illness, and quality of life.
Psychiatric Rehabilitation Journal, Vol.23, No.4, 323-332, 2000.

[19] P. T. Yanos, P. H. Lysaker, D. Roe. Internalized stigma as a barrier to improvement in vocational functioning among people with schizophrenia-spectrum disorders. Psychiatry Research, Vol.178, No.1, 211-213, 2010.

[20] S. G. Siris, D. Addington, J. M. Azorin, I. R. Falloon, J. Gerlach, S. R. Hirsch. Depression in schizophrenia: Recognition and management in the USA. Schizophrenia Research, Vol.47, No.2-3, 185-197, 2001.

[21] P. Werner, A. Avia, Y. Barak. Self-stigma, self-esteem and age in persons with schizophrenia. International Psychogeriatrics, Vol.20, No.01, 174-187, 2008.

[22] D. Kavanagh. Self-Efficacy and Depression. In R. Schwarzer. ed. Self-efficacy: Thought control of action, New York: Taylor \& Francis, 177-194, 2014.

[23] Y. Lee, M. J. Yang, J. L. Lai, N. M. Chiu, T. T. Chau. Development of the Taiwanese depression questionnaire. Chang Gung Medical Journal, Vol.23, No.11, 688-694, 2000.

[24] H. C. Triandis. Cross-cultural studies of individualism and collectivism. University of Nebraska Press, 1990.

[25] H. C. Triandis. Collectivism and individualism as cultural syndromes. Cross-Cultural Research, Vol.27, No.3-4, 155-180, 1993.

[26] G. Hofstede, M. Minkov. Cultures and organizations: Software of the mind. New York: McGraw-Hill, 1991.

[27] J. J. Arnett. The psychology of globalization. American Psychologist, Vol.57, No.10, 774-783, 2002.

[28] J. W. Berry, Y. H. Poortiga, S. M. Breugelmans. Cross-Cultural Psychology: Research and Applications, 3rd ed, New York: Cambridge University Press, 2011.

[29] H. C. Triandis, M. Gelfand. Converging measurement of horizontal and vertical individualism and collectivism. Journal of Personality and Social Psychology, Vol.74, No.1, 118-128, 1998. 